Original Article

\title{
Rapid Progression to Acute Respiratory Distress Syndrome: Review of Current Understanding of Critical Illness from Coronavirus Disease 2019 (COVID-19) Infection
}

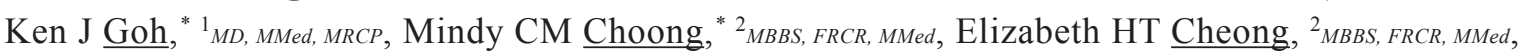
Shirin Kalimuddin, ${ }^{3,4}{ }_{M B B S, M R C P, M P H}$, Sewa Duu Wen, ${ }^{1} M B B S, M R C P$, Ghee Chee Phua, ${ }^{1} M B B S, M R C P$, Kian Sing Chan, ${ }^{5}$ MBBS, FRCPA, Salahudeen Haja Mohideen, ${ }^{2} M D, M R C P, F R C R$

\begin{abstract}
The outbreak of coronavirus disease 2019 (COVID-19) in December 2019 in the city of Wuhan in Mainland China has spread across the globe with $>100,000$ infected individuals and 3000 deaths reported in 93 countries as of 7 March 2020. We report a case of COVID-19 infection in a 64-year-old man who developed rapidly worsening respiratory failure and acute respiratory distress syndrome (ARDS) that required intubation. As the clinical spectrum of COVID-19 infection ranges from mild illness to ARDS with high mortality risk, there is need for research that identifies early markers of disease severity. Current evidence suggests that patients with advanced age, dyspnoea or pre-existing comorbidities should be monitored closely, especially at 1-2 weeks after symptom onset. It remains to be seen whether laboratory findings such as lymphopaenia or elevated lactate dehydrogenase may serve as early surrogates for critical illness or markers of disease recovery. Management of ARDS in COVID-19 patients remains supportive while we await results of drug trials. More studies are needed to understand the incidence and outcomes of ARDS and critical illness from COVID-19 infection which are important for critical care management of patients and resource planning.
\end{abstract}

Ann Acad Med Singapore 2020;49:108-18

Key words: Intensive Care, Mortality, Pneumonia, Risk factors

\section{Introduction}

The outbreak of coronavirus disease 2019 (COVID-19)_caused by severe acute respiratory syndrome coronavirus 2 (SARS-CoV-2) infectionwas first reported on 31 December 2019 in the city of Wuhan in Mainland China. ${ }^{1}$ On 30 January 2020, the World Health Organization (WHO) declared the outbreak a global health emergency; as of 7 March $2020,>100,000$ individuals in 93 countries had been infected by the virus. ${ }^{2}$ At this early stage of the outbreak, COVID-19 has already exceeded the total number of cases and deaths from Middle East Respiratory
Syndrome Coronavirus (MERS-CoV) and Severe Acute Respiratory Syndrome (SARS). ${ }^{3}$

On 23 January 2020, Singapore reported her first case of COVID-19 infection in a tourist from Wuhan. ${ }^{4}$ On 4 February 2020, the country reported the first cluster of local transmission. By 7 March 2020, there were 130 COVID-19 cases and approximately 15\% of them developed respiratory failure that required mechanical ventilation. ${ }^{5}$

In this report, we describe a patient who developed acute respiratory distress syndrome (ARDS) with rapid clinical deterioration. Unfortunately, not much is known

\footnotetext{
${ }^{1}$ Department of Respiratory and Critical Care Medicine, Singapore General Hospital, Singapore

${ }^{2}$ Department of Diagnostic Radiology, Singapore General Hospital, Singapore

${ }^{3}$ Department of Infectious Diseases, Singapore General Hospital, Singapore

${ }^{4}$ Duke-NUS Medical School, Singapore

${ }^{5}$ Division of Pathology, Singapore General Hospital, Singapore

"Co-authors

Address for Correspondence: Dr Ken Goh Junyang, Department of Respiratory and Critical Care Medicine, Singapore General Hospital, Outram Road, Singapore 169608.

Email: ken.goh.junyang@singhealth.com.sg
} 
about the clinical features and risk factors for ARDS and critical illness even as the number of COVID-19 cases continues to climb at an alarming rate throughout the world. However, recent published data suggested that advanced age and comorbidities such as cardiovascular disease may be associated with more severe disease. ${ }^{6}$ In this review, we examine current understanding of critical illness from COVID-19 infection and explore areas where research is urgently needed.

\section{Case Presentation}

A 64-year-old Chinese man presented with a fall that was preceded by dizziness. He reported dyspnoea and fever that lasted 1 day and 1 week, respectively, and had no significant past medical history. Prior to presentation, he worked as a taxi driver and reported ferrying passengers who were tourists from Mainland China. He denied a history of recent travel or contact with individuals infected by COVID-19.

Clinically, he was alert and comfortable; his temperature was $39.0^{\circ} \mathrm{C}$, oxygen saturation was $92 \%$ on room air and respiratory rate was 20 breaths $/ \mathrm{min}$. On examination, his lungs were clear to auscultation. Laboratory investigations revealed haemoglobin $14.1 \mathrm{~g} / \mathrm{dL}$, white blood cell count $4.6 \times 10^{9} / \mathrm{L}$, lymphopaenia with lymphocyte count 0.23 $\times 10^{9} / \mathrm{L}$ (normal $1-3 \times 10^{9} / \mathrm{L}$ ) and platelet count 147 $\times 10^{9} / \mathrm{L}$. C-reactive protein was elevated at $87.9 \mathrm{mg} / \mathrm{L}$ (normal $0.2-9.1 \mathrm{mg} / \mathrm{L}$ ) and procalcitonin was $0.55 \mu \mathrm{g} / \mathrm{L}$ (normal $<0.50 \mu \mathrm{g} / \mathrm{L}$ ).

On admission, findings of liver and renal function tests and serum lactate were normal, but chest radiograph showed subtle ground-glass opacities in lower zones with minor interstitial changes at the right base and atelectasis in left lower zone. Consolidation or pleural effusion was absent (Fig. 1A). In view of his recent contact with tourists from Mainland China, he was immediately isolated in an airborne infection isolation room (AIIR). Throat swab on real-time reverse transcriptase-polymerase chain reaction (RT-PCR) tested positive for SARS-CoV-2 and he was started on lopinavir/ritonavir (Kaletra) on day 2 of admission. Oxygen saturation was stable on $3 \mathrm{~L} / \mathrm{min}$ flow of oxygen. Apart from a respiratory rate of $18-20$ breaths/min, all vital signs were normal.

Within 48 hours of presentation, however, he deteriorated rapidly with severe hypoxemic respiratory failure that required high-flow oxygen supplementation with a face mask. Repeat chest radiograph showed rapid development of bilateral diffuse ground-glass opacities (Fig. 1B) and he was intubated and initiated on mechanical ventilation.

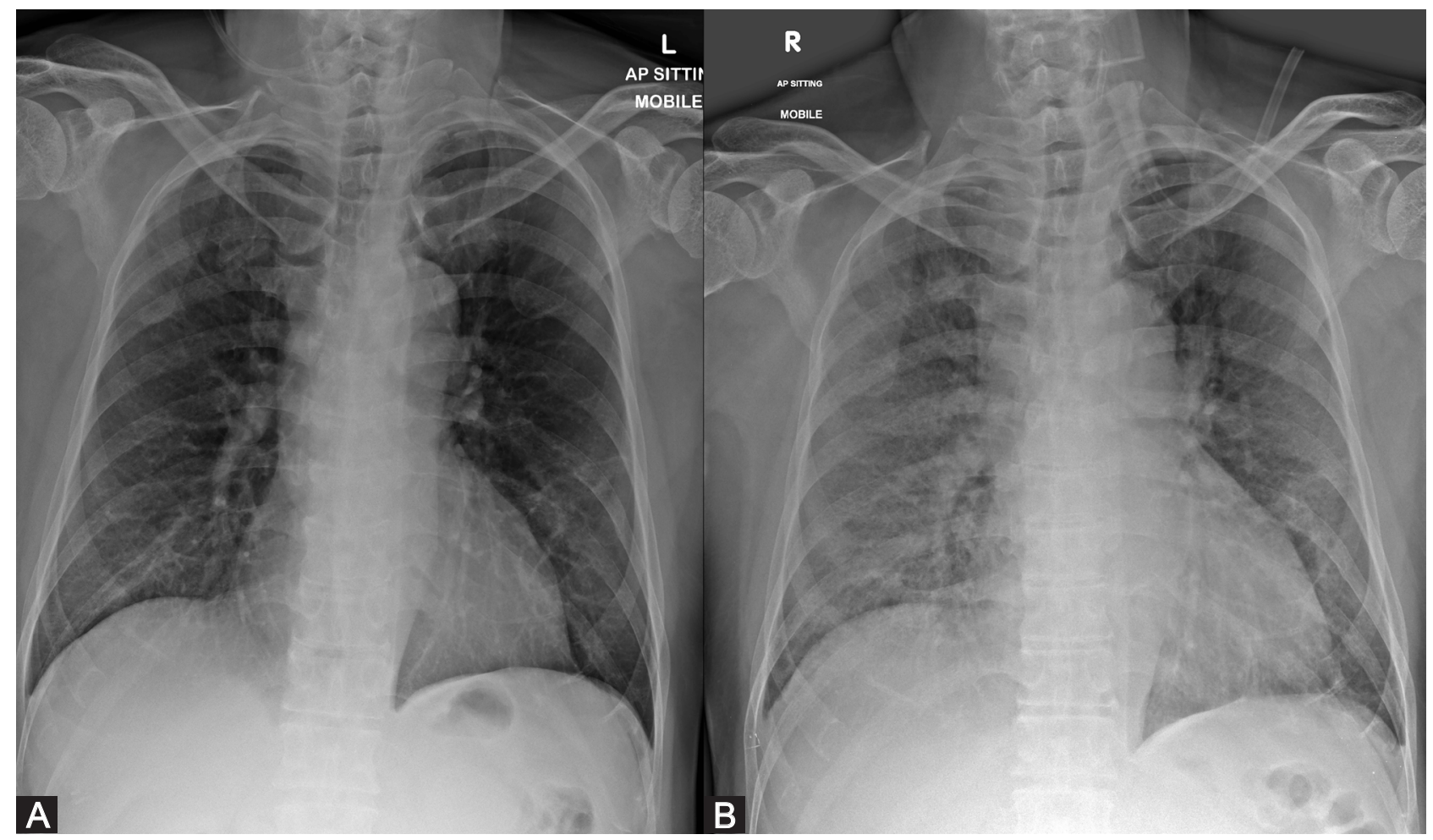

Fig. 1. A: On admission, chest radiograph showed minimal ground-glass opacities in lower zones with interstitial thickening in right base and atelectasis in left lower zone. No consolidation or pleural effusion was evident. B: On day 2, repeat chest radiograph showed rapid development of diffuse groundglass opacities bilaterally. The patient was intubated on the same day. 
To minimise risk of viral transmission to health workers during intubation, a high-efficiency particulate air mechanical filter was used with bag-valve-mask interface and an emphasis on adequate preoxygenation and rapid sequence induction to minimise dispersion of respiratory droplets. After initial stabilisation, arterial blood gas showed partial pressure of oxygen $\left(\mathrm{PaO}_{2}\right)$ of $80 \mathrm{mmHg}$, fraction of inspired oxygen $\left(\mathrm{FiO}_{2}\right)$ of 0.7 and positive end-expiratory pressure (PEEP) of $10 \mathrm{cmH}_{2} \mathrm{O}$ that were consistent with moderate to severe ARDS $\left(\mathrm{PaO}_{2} /\right.$ $\mathrm{FiO}_{2}$ 114). ${ }^{7}$ Despite deep sedation, significant ventilator dyssynchrony was observed, and neuromuscular blockade was initiated to maintain lung protective ventilation.
During this period of paralysis, oxygenation improved. On day 2 of mechanical ventilation, he was supported with volume-controlled ventilation: tidal volume $350 \mathrm{~mL}\left(5.0 \mathrm{~mL} / \mathrm{kg}\right.$ predicted body weight), $\mathrm{FiO}_{2}$ 0.4 , PEEP $10 \mathrm{cmH}_{2} \mathrm{O}$ and respiratory rate 30 breaths/ min with a plateau pressure of $20 \mathrm{cmH}_{2} \mathrm{O}$. Repeat arterial blood gas showed $\mathrm{pH}$ 7.31, partial pressure of carbon dioxide $51 \mathrm{mmHg}$ and $\mathrm{PaO}_{2} 78 \mathrm{mmHg}$. He did not require prone ventilation.

On day 8, computed tomography (CT) of thorax revealed diffuse ground-glass opacities and consolidation in the dependent segments of both lungs (Fig. 2), findings that were consistent with ARDS. He was started on

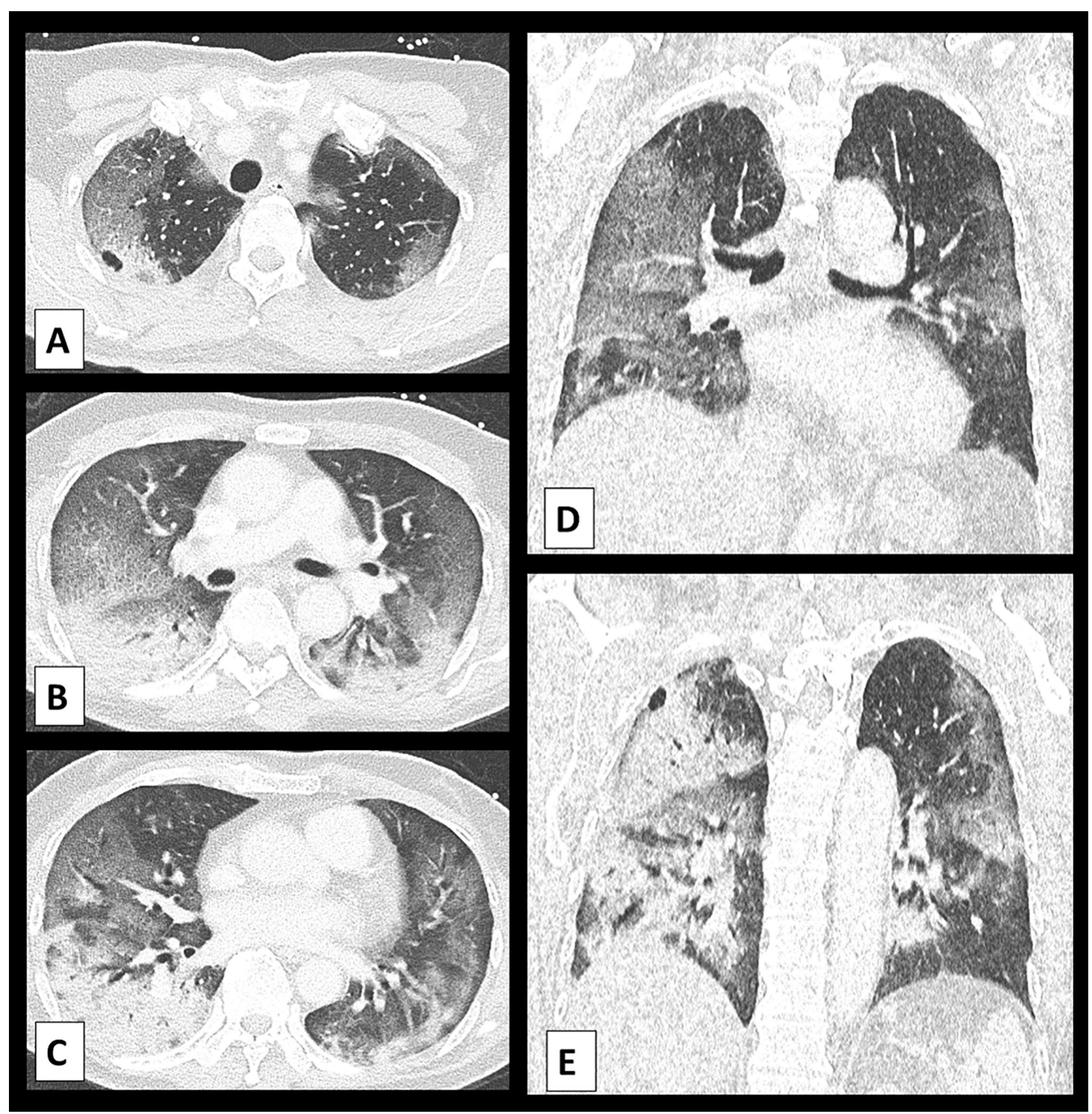

Fig. 2. Computed tomography (CT) of lung. A: Axial contrast-enhanced CT image showed ground-glass opacities that predominate in upper lobes with stark thin rim of subpleural sparing. B: Axial CT image showed mild, smooth intralobular septal thickening that gave the appearance of "crazy paving”. C: Axial CT image showed consolidation in dependent segments of both lungs with an asymmetric distribution that involved predominantly the right lower lobe. D and E: Coronal CT images showed an incidental small, thin-walled subpleural cyst in right upper lobe that likely represents a pneumatocele. Neither intrathoracic lymphadenopathy nor pleural effusion was observed. 
empirical broad-spectrum antibiotics, but these were discontinued after 8 days when all bacterial cultures returned negative. Despite withholding of sedative and analgesia agents, Glasgow Coma Scale remained depressed and full recovery was seen only after all sedatives were discontinued 4 days later. No metabolic disturbances were observed and brain $\mathrm{CT}$ was normal.

On day 10 , his ventilatory requirements increased with a concurrent rise in purulent endotracheal tube (ETT) secretions and development of new left midzone consolidation on chest radiograph (Fig. 3). Pseudomonas aeruginosa was isolated from ETT aspirates. He completed 7 days of culture-directed antibiotics for ventilator-associated pneumonia. After 11 days of mechanical ventilation, he was successfully extubated on day 14.

During his stay in the Intensive Care Unit (ICU), RT-PCR for SARS-CoV-2 was performed on ETT and throat swab specimens on alternate days until the first negative culture was obtained on day 15 of admission, which was approximately 3 weeks after symptom onset. A day later, lymphopaenia resolved. Incidentally, he had diarrhoea during the first 2 days of admission before lopinavir/ritonavir was initiated and SARS-CoV-2 was detected in stool samples on RT-PCR; results of Clostridium difficile toxin assays were negative. The events and progress of his ICU stay are illustrated in Figure 4.

\section{Discussion}

In our patient, we described the clinical course of COVID-19 infection that developed rapidly into ARDS requiring intubation. This case highlighted the need to identify risk factors associated with critical illness so that at-risk patients can be promptly identified and closely monitored. It also prompts a discussion of our current understanding of critical illness from COVID-19 infection after the outbreak was declared a global pandemic by the WHO on 11 March $2020 .{ }^{8}$

\section{Incidence of ARDS and Critical Illness}

There is wide variability in the reported incidence of ARDS or critical illness from COVID-19 infection. As shown in Table 1, initial studies from hospitals in Wuhan city in Mainland China had reported an alarming incidence of ARDS (17-29\%) and critical illness that required ICU admission (23-32\%). ${ }^{9-12}$ The reported incidence may be underestimated since most patients remained hospitalised in some of the studies. ${ }^{10,11}$ Conversely, the reported incidence of critical illness in areas further away from the epicentre of the outbreak in Wuhan city appeared to be lower.

In their study of 1099 patients from 30 provinces in Mainland China, Guan et al reported an incidence of $3-5 \%$ for ARDS or admission to ICU. ${ }^{13}$ In their study, most patients (94\%) remained hospitalised at the time of writing, again suggesting that outcomes may be significantly underestimated. Consequently, their study is better described as a cross-sectional survey of hospitalised patients. ${ }^{13}$ Differences in age and comorbidities may also account for these differences (Table 1)..$^{14,15}$

The true incidence of critical illness is difficult to determine due to differences in resources available for diagnostic testing, contact tracing and surveillance. In Zhejiang Province, individuals with respiratory symptoms or significant contact history with COVID-19

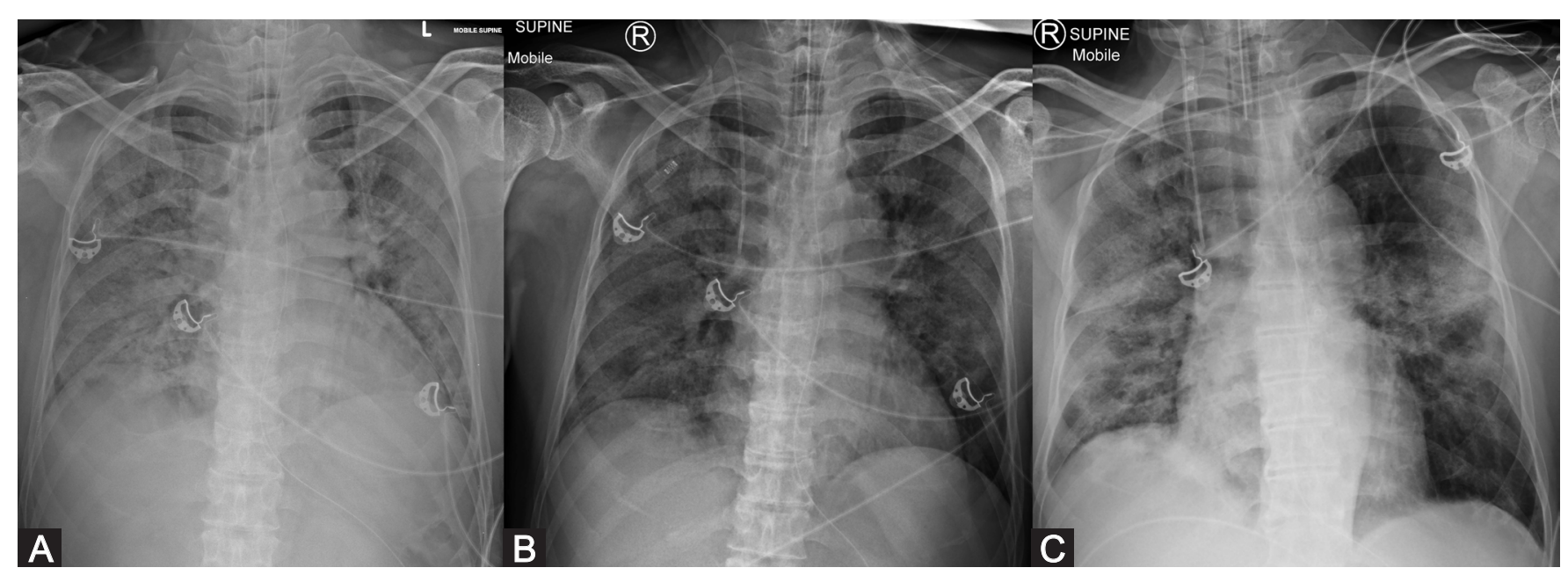

Fig. 3. A: Chest radiograph after endotracheal intubation. B: On day 4, chest radiograph showed mild improvement in extensive airspace opacification. $\mathrm{C}$ : On day 11, chest radiograph showed interval development of patchy consolidation in right lung and focal consolidation in left mid-zone. A nasogastric tube (A, B and C) and right internal jugular venous catheter (B and $\mathrm{C}$ ) were inserted. 


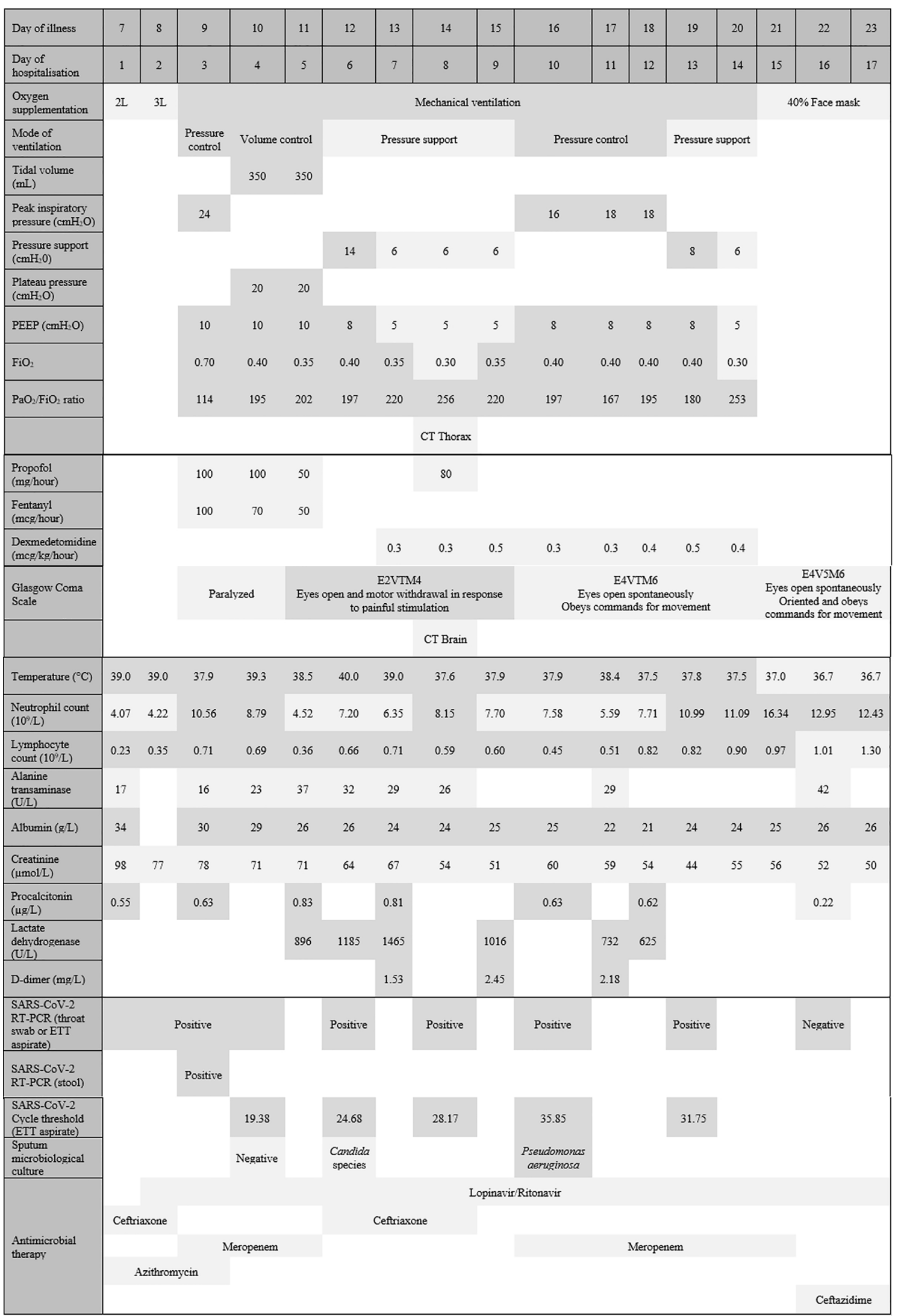

Fig. 4. Clinical course of patient on admission. COVID-19: Coronavirus disease 2019; CT: Computed tomography; ETT: Endotracheal tube; FiO Fraction of inspired oxygen; $\mathrm{PaO}_{2}$ : Partial pressure of oxygen; PEEP: Positive end-expiratory pressure; RT-PCR: Reverse transcriptase-polymerase chain reaction; SARS-CoV-2: Severe acute respiratory syndrome coronavirus 2 


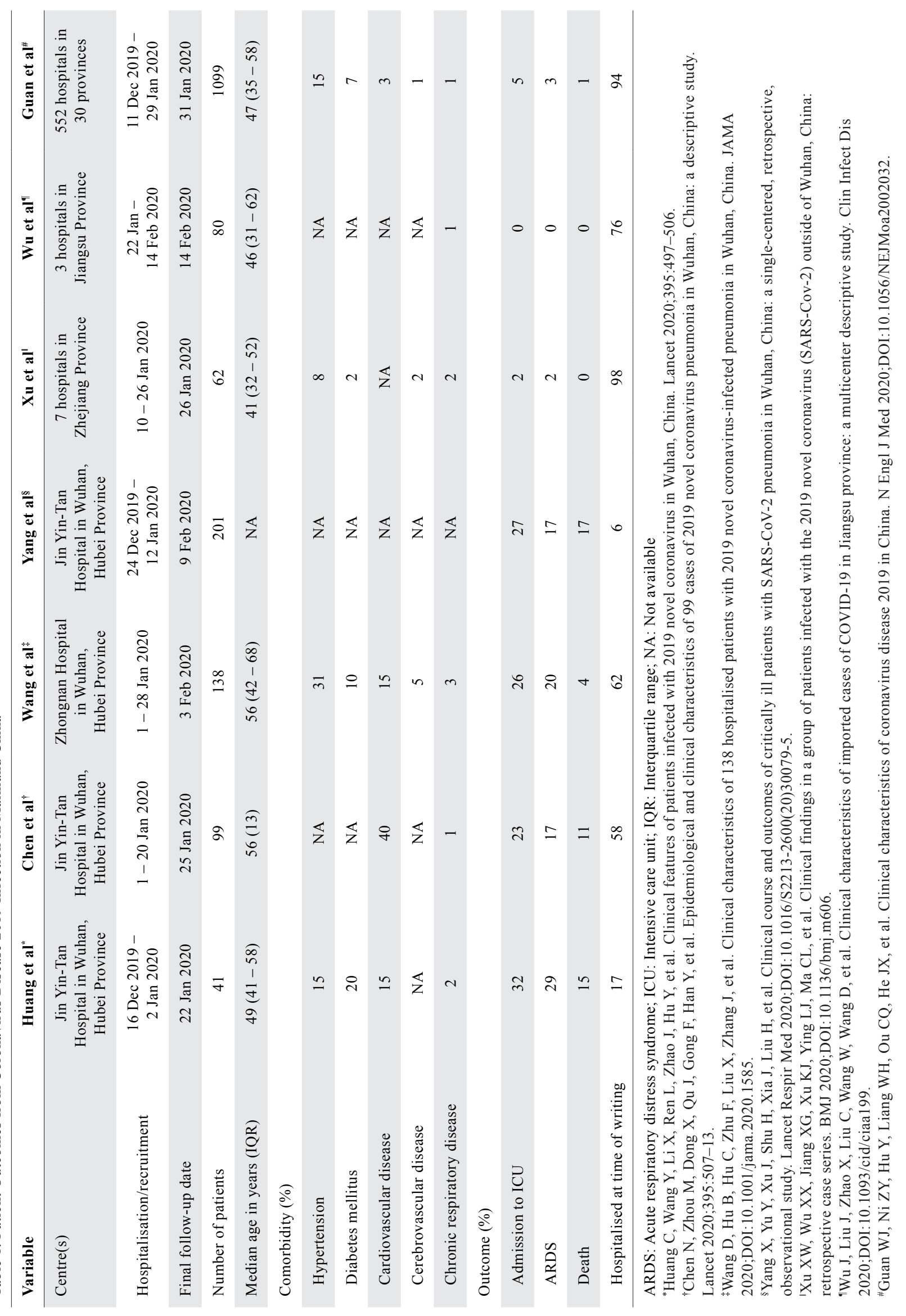


patients were advised to visit hospitals and ARDS was only reported in 1 out of 62 hospitalised patients. ${ }^{14}$ Nevertheless, it is clear that the clinical spectrum of COVID-19 infection ranges widely from asymptomatic individuals to those with a mild form of the illness to patients with critical illness and with high mortality risk. ${ }^{6}$ Large multicentre studies from other countries with adequate follow-up to hospital discharge or death will shed more light on the incidence of critical illness that is crucial to resource planning of health services from around the world.

\section{Critical Illness from COVID-19 Infection: Clinical Features and Risk Factors}

In our patient, the observation of rapid clinical deterioration is concerning. With the wide spectrum of clinical severity observed in COVID-19 patients, it is necessary to identify patients who are at higher risk of critical illness. Unfortunately, the risk factors and clinical characteristics of ARDS from COVID-19 infection are still not fully known or understood. What appears to be a consistent finding, however, is that ARDS and critical illness mostly develop between 1-2 weeks after symptom onset. ${ }^{9,11,12}$ Similar to findings from published studies (Table 2), our patient developed ARDS on day 9 after symptom onset. ${ }^{9,11}$

Like MERS-CoV ${ }^{16}$ and SARS ${ }^{17}$, patients with older age, comorbidities (such as cardiovascular and cerebrovascular diseases) and dyspnoea appeared to have worse outcomes. ${ }^{9,11,12}$ Median age of ICU patients was 63-6 years compared to $46-51$ years in non-ICU patients. ${ }^{11,13}$ A similar finding for age was also seen between survivors and non-survivors. ${ }^{9,18}$ While cough and fever were observed in most patients, dyspnoea was reported in about $30-50 \%$ of patients; based on studies from Wuhan city in Mainland China, approximately half of patients with dyspnoea required ICU admission. ${ }^{9}, 11$ Pre-existing chronic lung disease is also a concern. In the study by Guan et al, more than half of patients with chronic obstructive pulmonary disease and COVID-19 infection were admitted to ICU or required mechanical ventilation. ${ }^{11}$

The age of our patient (64 years old) and presence of dyspnoea were worrisome features. Additionally, initial blood tests revealed significant lymphopaenia which has been reported to be associated with critical illness. ${ }^{9,11,18}$ Neutrophilia, hypoalbuminaemia and elevated levels of lactate dehydrogenase (LDH) and D-dimer were other markers of critical illness in COVID-19 infection that were seen in our patient. ${ }^{9,11,18}$ These observations appear to be consistent with SARS, where multivariate analysis had identified elevated LDH and neutrophilia as markers that were associated with worse outcomes. ${ }^{17}$ However, these markers are non-specific and are commonly found in critically ill patients.

For clinicians, an early surrogate of disease severityideally before the onset of critical illness-is useful. The issue of whether the degree of lymphopaenia or LDH elevation can be early markers of disease severity-or even a surrogate for disease recovery from COVID-19 infection-is still unclear. In their study of patients who were not critically ill, Young et al reported a decline in viral loads - based on RT-PCR cycle thresholds - after a peak was reached shortly after symptom onset. ${ }^{19}$ This finding was also observed in our patient. However, it remains to be seen whether trends in viral loads can serve as a surrogate for disease recovery.

In our patient, chest CT showed extensive multilobar ground-glass changes with intralobular septal thickening and more confluent consolidation in the dependent portions of the lungs. Despite the peripheral location of the ground-glass changes, there were thin rims of subpleural sparing which-to the best of our knowledge - have not been reported previously. Nevertheless, ground-glass opacities with or without consolidation - with posterior and peripheral predominance - appear to be the most common finding in COVID-19 pneumonia, ${ }^{20,21}$ MERS-CoV and SARS. ${ }^{22,23}$ In our patient, lack of thoracic lymphadenopathy and pleural effusions are also consistent with reported findings of COVID-19 infection. ${ }^{20,21}$

Findings of normal chest images, however, do not rule out the development of severe illness. Guan et al reported that up to $23 \%$ and $12 \%$ of patients who required ICU admission had normal chest radiographs and CT images, respectively. ${ }^{13}$ Despite the rapid deterioration observed in our patient, only subtle ground-glass and interstitial changes were seen in the initial chest radiograph. This observation is limited by the fact that it is based on a single case report. However, with more studies, we will hopefully be able to shed more light on the clinical course of patients who develop critical illness. Nevertheless, it is prudent for clinicians to closely monitor patients with advanced age, comorbidities or dyspnoea, especially at 1-2 weeks after symptom onset.

Interestingly, our patient remained in a semi-conscious state for almost 4 days without sedation and opioid therapy. No abnormalities were seen on brain CT and no significant metabolic disturbances could be found to explain the degree of unconsciousness. Subsequently, he regained full consciousness without any neurological deficit. Although septic encephalopathy is a likely diagnosis, it is also possible that this outcome could be attributed to the accumulation of fentanyl from 
Table 2. Patient Outcomes from Coronavirus Disease 2019 Infection in Mainland China Who Required ICU Admission

\begin{tabular}{|c|c|c|c|c|c|}
\hline Variable & Huang et $\mathbf{a l}^{*}$ & Chen et $\mathbf{a l}^{\dagger}$ & Wang et $\mathbf{a l}^{\ddagger}$ & Yang et $\mathbf{a l}^{\S}$ & Guan et al' \\
\hline Centre(s) & $\begin{array}{c}\text { Jin Yin-Tan } \\
\text { Hospital in Wuhan, } \\
\text { Hubei Province }\end{array}$ & $\begin{array}{c}\text { Jin Yin-Tan } \\
\text { Hospital in Wuhan, } \\
\text { Hubei Province }\end{array}$ & $\begin{array}{c}\text { Zhongnan Hospital } \\
\text { in Wuhan, Hubei } \\
\text { Province }\end{array}$ & $\begin{array}{c}\text { Jin Yin-Tan } \\
\text { Hospital in Wuhan, } \\
\text { Hubei Province }\end{array}$ & $\begin{array}{l}552 \text { hospitals in } \\
30 \text { provinces }\end{array}$ \\
\hline Hospitalisation/recruitment & $\begin{array}{l}16 \text { Dec } 2019- \\
2 \text { Jan } 2020\end{array}$ & $1-20$ Jan 2020 & $1-28$ Jan 2020 & $\begin{array}{l}24 \text { Dec } 2019- \\
12 \text { Jan } 2020\end{array}$ & $\begin{array}{l}11 \text { Dec } 2019- \\
29 \text { Jan } 2020\end{array}$ \\
\hline Number of patients & 13 & 23 & 36 & 52 & $67^{\circ}$ \\
\hline Median age in years (IQR) & $49(41-61)$ & NA & $66(57-78)$ & $60(13)$ & $63(53-71)$ \\
\hline \multicolumn{6}{|l|}{ Comorbidity (\%) } \\
\hline Hypertension & 15 & NA & 58 & NA & NA \\
\hline Cardiovascular disease & 23 & NA & 25 & NA & 27 \\
\hline Cerebrovascular disease & NA & NA & 17 & 14 & 6 \\
\hline Chronic respiratory disease & 8 & NA & 8 & 8 & 10 \\
\hline $\begin{array}{l}\text { Symptom onset to ARDS in days, } \\
\text { median (IQR) }\end{array}$ & $9(8-14)$ & NA & $8(6-12)$ & NA & NA \\
\hline $\begin{array}{l}\text { Symptom onset to ICU admission } \\
\text { in days, median (IQR) }\end{array}$ & $11(8-17)$ & NA & $10(6-12)$ & $10(7-13)$ & NA \\
\hline \multicolumn{6}{|l|}{ ICU outcome $(\%)$} \\
\hline Nosocomial infection & 31 & NA & NA & 14 & NA \\
\hline Shock & 23 & 17 & 31 & 35 & 13 \\
\hline ARDS & 85 & 74 & 75 & 67 & 40 \\
\hline Mechanical ventilation & 15 & 17 & 47 & 71 & 37 \\
\hline ECMO & 15 & 12 & 11 & 12 & 8 \\
\hline Death & 38 & 48 & 17 & $62^{\#}$ & 22 \\
\hline Hospitalised at end of study & 8 & NA & 58 & 23 & 76 \\
\hline $\begin{array}{l}\text { On mechanical ventilation at end } \\
\text { of study }\end{array}$ & NA & NA & 17 & 1 & NA \\
\hline
\end{tabular}

ARDS: Acute respiratory distress syndrome; ECMO: Extracorporeal membrane oxygenation; ICU: Intensive care unit; IQR: Interquartile range; NA: Not available

"Huang C, Wang Y, Li X, Ren L, Zhao J, Hu Y, et al. Clinical features of patients infected with 2019 novel coronavirus in Wuhan, China. Lancet 2020;395:497-506.

Chen N, Zhou M, Dong X, Qu J, Gong F, Han Y, et al. Epidemiological and clinical characteristics of 99 cases of 2019 novel coronavirus pneumonia in Wuhan, China: a descriptive study. Lancet 2020;395:507-13.

*Wang D, Hu B, Hu C, Zhu F, Liu X, Zhang J, et al. Clinical characteristics of 138 hospitalised patients with 2019 novel coronavirus-infected pneumonia in Wuhan, China. JAMA 2020;DOI:10.1001/jama.2020.1585.

${ }^{\S}$ Yang X, Yu Y, Xu J, Shu H, Xia J, Liu H, et al. Clinical course and outcomes of critically ill patients with SARS-CoV-2 pneumonia in Wuhan, China: a single-centered, retrospective, observational study. Lancet Respir Med 2020;DOI:10.1016/S2213-2600(20)30079-5.

'Guan WJ, Ni ZY, Hu Y, Liang WH, Ou CQ, He JX, et al. Clinical characteristics of coronavirus disease 2019 in China. N Engl J Med 2020;DOI:10.1056/NEJMoa2002032.

'Composite outcome of death, ICU admission or mechanical ventilation.

"28-day ICU mortality. 
inhibition of cytochrome $\mathrm{P} 450$ by ritonavir, which is another important consideration for intensivists in their management of such patients. ${ }^{24}$

\section{Outcomes and Mortality of Critical Illness from COVID-19 Infection}

Critical illness from COVID-19 infection is associated with high mortality risk even though its estimated case fatality rate of $3.4 \%{ }^{2}$ is significantly lower than MERS-CoV $(34.4 \%)^{3}$ and SARS (11\%). ${ }^{25}$ In Jin YinTan Hospital in Wuhan city, mortality rate of ICU patients was reported to range between $38-62 \%$ and $>10 \%$ of patients required extracorporeal membrane oxygenation (ECMO). ${ }^{9,10,12}$ Yang et al reported a 28 day mortality rate of $62 \%$ in patients who required ICU care; in patients who developed ARDS, the mortality rate was $74 \% .{ }^{12}$ In-hospital mortality rate was likely to be higher since most survivors were still hospitalised, 3 patients were on mechanical ventilation and 1 patient was on ECMO. ${ }^{12}$ Indeed, the mortality rates that were being reported were alarming since they were higher than that commonly seen in severe ARDS attributed to other causes and conditions. ${ }^{26}$

It is possible, however, that the quality of health services was severely compromised and resulted in poorer outcomes in Wuhan city after health workers there were overwhelmed by the exponential increase in the number of COVID-19 patients. A recent publication by Xie et al reported severe shortages in ventilators and only about $25 \%$ of patients who died had received invasive mechanical intubation. ${ }^{27}$ Additionally, most patients were supported with high-flow nasal cannula (HFNC) and non-invasive ventilation (NIV) and received systemic corticosteroids..$^{912}$ It is unclear whether delayed intubation or systemic corticosteroids might have adversely affected the outcomes in some patients. ${ }^{28}$ As was the case with our patient, up to a third of critically ill patients developed nosocomial or secondary bacterial infections and intensivists who manage such patients must remain vigilant since early administration of antibiotics may potentially improve outcomes. ${ }^{9,12}$ Finally, data is still lacking on duration of mechanical ventilation or ECMO in survivors since such information is important for critical care management and resource planning.

\section{Clinical Management of Critical Illness from COVID-19 Infection}

In the absence of studies on ARDS induced by COVID-19 infection, principles of clinical management of patients should be consistent with established guidelines for ARDS. The WHO has published similar guidelines for severe respiratory infections from COVID-19 infection..$^{29}$ In our patient, we adopted lung protective ventilation, conservative fluid strategy and neuromuscular blockade to manage moderate to severe ARDS. Neuromuscular blockade was initiated after significant ventilator dyssynchrony was seen despite deep sedation.

Since there was a lack of clear benefit with the use of HFNC in acute respiratory failure and high failure rates were observed with the use of NIV in MERS-CoV, ${ }^{30}$ the management of our patient was therefore guided by the principles of conventional oxygen therapy and early intubation. The presumed benefit of lopinavir/ ritonavir was extrapolated from the management of SARS patients. ${ }^{31,32}$ Remdesivir - a broad-spectrum prodrug that inhibits RNA-dependent RNA-polymerase activity - has shown promise in in vitro studies and is currently under evaluation in a randomised, controlled clinical trial (NCT04257656). ${ }^{33}$

To date, no antiviral therapy has proven effective against COVID-19 infection. In our patient, corticosteroids were not administered since there was a lack of evidence to support their efficacy; ${ }^{34}$ The use of corticosteroids is associated with worse outcomes or delayed viral clearance in SARS and MERS-CoV patients. ${ }^{35,36}$ Finally, infection control and prevention is a key component of ICU management. ${ }^{37}$ The emphasis is on use of appropriate personal protective equipment and practice of standard contact and airborne precautions with eye protection by health workers. Known or suspected COVID-19 patients should be isolated in AIIR and measures to minimise aerosolisation or dispersion of respiratory droplets by patients should be stringently practised..$^{38}$

Interestingly, our patient had diarrhoea and SARS$\mathrm{CoV}-2$ was detected in his stool samples. A small study of 8 patients by Young et al also reported that the stools of 4 of them tested positive for SARS-CoV-2 on RT-PCR. ${ }^{19}$ These findings suggest that viral transmission through the faecal-oral route may be a concern in patients with COVID-19 infection. ${ }^{39}$

\section{Conclusion}

The wide clinical spectrum of COVID-19 infection ranges from individuals who are asymptomatic to those who present with critical illness and with high mortality risk. Since there is a likelihood that patients will deteriorate rapidly, more studies are needed to identify early predictive markers of the more severe form of the disease. In the absence of a clear, dysregulated host response to infection, abnormal laboratory findings such as lymphopaenia or elevated LDH may potentially serve as early surrogate markers for the development of 
critical illness. While we await results of studies that can shed more light on definitive treatment options, management of ARDS induced by COVID-19 infection is mainly supportive and does not differ from that caused by other conditions other than a need to adhere strictly to established infection control measures.

\section{Acknowledgements}

The authors would like to thank their clinical research coordinators Natalie Lee and Christina Titin, members of the Infection Prevention and Control team and radiographers from the Department of Diagnostic Radiology. They also acknowledge staff of the Respiratory and Critical Care and Infectious Disease departments, respiratory therapists, nurses and all staff in Singapore General Hospital for their fortitude and dedication to provide the best care for their patients.

\section{REFERENCES}

1. Wuhan Municipal Health Commission. Report of clustering pneumonia of unknown etiology in Wuhan City. Available at: http:// wjw.wuhan.gov.cn/front/web/showDetail/2019123108989. Accessed on 24 February 2020.

2. World Health Organization. Coronavirus Disease 2019 (COVID-19), Situation Report 47. Available at: https://www.who.int/docs/ default-source/coronaviruse/situation-reports/20200307-sitrep-47covid-19.pdf. Accessed on 1 March 2020.

3. Park M, Thwaites RS, Openshaw PJM. COVID-19: lessons from SARS and MERS. Eur J Immunol 2020;50:308-11.

4. Wong JEL, Leo YS, Tan CC. COVID-19 in Singapore-current experience: critical global issues that require attention and action. JAMA 2020;DOI:10.1001/jama.2020.2467.

5. Ministry of Health, Singapore. Updates on COVID-19 (Coronavirus Disease 2019) Local Situation. Available at: https://www.moh.gov. sg/covid-19. Accessed on 10 March 2020.

6. Wu Z, McGoogan JM. Characteristics of and important lessons from the coronavirus disease 2019 (COVID-19) outbreak in China: summary of a report of 72,314 cases from the Chinese Center for Disease Control and Prevention. JAMA 2020;DOI:10.1001/ jama.2020.2648.

7. Ferguson ND, Fan E, Camporota L, Antonelli M, Anzueto A, Beale $\mathrm{R}$, et al. The Berlin definition of ARDS: an expanded rationale, justification, and supplementary material. Intensive Care Med 2012;38:1573-82.

8. World Health Organization. Director-General's opening remarks at the media briefing on COVID-19, 11 March 2020. Available: https:// www.who.int/dg/speeches/detail/who-director-general-s-openingremarks-at-the-media-briefing-on-covid-19---11-march-2020. Accessed on 11 March 2020.

9. Huang C, Wang Y, Li X, Ren L, Zhao J, Hu Y, et al. Clinical features of patients infected with 2019 novel coronavirus in Wuhan, China. Lancet 2020;395:497-506.

10. Chen N, Zhou M, Dong X, Qu J, Gong F, Han Y, et al. Epidemiological and clinical characteristics of 99 cases of 2019 novel coronavirus pneumonia in Wuhan, China: a descriptive study. Lancet 2020;395:507-13.

11. Wang D, Hu B, Hu C, Zhu F, Liu X, Zhang J, et al. Clinical characteristics of 138 hospitalised patients with 2019 novel coronavirusinfected pneumonia in Wuhan, China. JAMA 2020;DOI:10.1001/ jama.2020.1585.
12. Yang X, Yu Y, Xu J, Shu H, Xia J, Liu H, et al. Clinical course and outcomes of critically ill patients with SARS-CoV-2 pneumonia in Wuhan, China: a single-centered, retrospective, observational study. Lancet Respir Med 2020;DOI:10.1016/S2213-2600(20)30079-5.

13. Guan WJ, Ni ZY, Hu Y, Liang WH, Ou CQ, He JX, et al. Clinical characteristics of coronavirus disease 2019 in China. N Engl J Med 2020;DOI:10.1056/NEJMoa2002032.

14. Xu XW, Wu XX, Jiang XG, Xu KJ, Ying LJ, Ma CL, et al. Clinical findings in a group of patients infected with the 2019 novel coronavirus (SARS-Cov-2) outside of Wuhan, China: retrospective case series. BMJ 2020;DOI:10.1136/bmj.m606.

15. Wu J, Liu J, Zhao X, Liu C, Wang W, Wang D, et al. Clinical characteristics of imported cases of COVID-19 in Jiangsu province: a multicenter descriptive study. Clin Infect Dis 2020;DOI:10.1093/cid/ciaa199.

16. Ahmed AE. The predictors of 3- and 30-day mortality in 660 MERSCoV patients. BMC Infect Dis 2017;17:615.

17. Leong HN, Earnest A, Lim HH, Chin CF, Tan CSH, Puhaindran E, et al. SARS in Singapore-predictors of disease severity. Ann Acad Med Singapore 2006;35:326-31.

18. Ruan Q, Yang K, Wang W, Jiang L, Song J. Clinical predictors of mortality due to COVID-19 based on an analysis of data of 150 patients from Wuhan, China. Intensive Care Med 2020;DOI: 10.1007/ s00134-020-05991-x.

19. Young BE, Ong SWX, Kalimuddin S, Low JG, Tan SY, Loh J, et al. Epidemiologic features and clinical course of patients infected with SARS-CoV-2 in Singapore. JAMA 2020;DOI:10.1001/ jama.2020.3204.

20. Song F, Shi N, Shan F, Zhang Z, Shen J, Lu H, et al. Emerging 2019 novel coronavirus (2019-nCoV) pneumonia. Radiology 2020;295:210-7.

21. Chung M, Bernheim A, Mei X, Zhang N, Huang M, Zeng X, et al. CT imaging features of 2019 novel coronavirus (2019-nCoV). Radiology 2020;295:202 -7.

22. Das KM, Lee EY, Langer RD, Larsson SG. Middle East respiratory syndrome coronavirus: what does a radiologist need to know? AJR Am J Roentgenol 2016;206:1193-201.

23. Ooi GC, Ma D. SARS: radiological features. Respirology 2003;8:S15-19.

24. Bruce RD, Moody DE, Altice FL, Gourevitch MN, Friedland GH. A review of pharmacological interactions between HIV or hepatitis $\mathrm{C}$ virus medications and opioid agonist therapy: implications and management for clinical practice. Expert Rev Clin Pharmacol $2013 ; 6: 249-69$.

25. World Health Organization. Consensus document on the epidemiology of severe acute respiratory syndrome (SARS). Available at: https:// apps.who.int/iris/handle/10665/70863. Accessed on 1 March 2020.

26. Bellani G, Laffey JG, Pham T, Fan E, Brochard L, Esteban A, et al. Epidemiology, patterns of care, and mortality for patients with acute respiratory distress syndrome in intensive care units in 50 countries. JAMA 2016;315:788-800.

27. Xie J, Tong Z, Guan X, Du B, Qiu H, Slutsky AS. Critical care crisis and some recommedations during the COVID-19 epidemic in China. Intensive Care Med 2020;DOI:10.1007/s00134-020-05979-7.

28. Kang BJ, Koh YS, Lim CM, Huh JW, Baek SH, Han MJ, et al. Failure of high-flow nasal cannula therapy may delay intubation and increase mortality. Intensive Care Med 2015;41:623-32.

29. World Health Organization. Clinical management of severe acute respiratory infection when novel coronavirus $(\mathrm{nCoV})$ infection is suspected: interim guidance. Available at: https://www.who.int/ publications-detail/clinical-management-of-severe-acute-respiratoryinfection-when-novel-coronavirus-(ncov)-infection-is-suspected. Accessed on 20 February 2020. 
30. Arabi YM, Arifi AA, Balkhy HH, Najm H, Aldawood AS, Ghabashi A, et al. Clinical course and outcomes of critically ill patients with Middle East respiratory syndrome coronavirus infection. Ann Intern Med 2014;160:389-97.

31. Chu CM, Cheng VCC, Hung IFN, Wong MML, Chan KH, Chan KS, et al. Role of lopinavir/ritonavir in the treatment of SARS: initial virological and clinical findings. Thorax 2004;59:252-6.

32. Chan KS, Lai ST, Chu CM, Tsui E, Tam CY, Wong MML, et al. Treatment of severe acute respiratory syndrome with lopinavir/ ritonavir: a multicentre retrospective matched cohort study. Hong Kong Med J 2003;9:399-406.

33. Wang M, Cao R, Zhang L, Yang X, Liu J, Xu M, et al. Remdesivir and chloroquine effectively inhibit the recently emerged novel coronavirus (2019-nCoV) in vitro. Cell Res 2020;30:269-71.

34. Russell CD, Millar JE, Baillie JK. Clinical evidence does not support corticosteroid treatment for 2019-nCoV lung injury. Lancet 2020;395:473-5.
35. Auyeung TW, Lee JSW, Lai WK, Choi CH, Lee HK, Lee JS, et al. The use of corticosteroid as treatment in SARS was associated with adverse outcomes: a retrospective cohort study. J Infect 2005;51:98-102.

36. Arabi YM, Mandourah Y, Al-Hameed F, Sindi AA, Almekhlafi GA, Hussein MA, et al. Corticosteroid therapy for critically ill patients with Middle East respiratory syndrome. Am J Respir Crit Care Med 2018;197:757-67.

37. Centers for Disease Control and Prevention. Coronavirus Disease 2019 (COVID-19): Interim Infection Prevention and Control Recommendations. Available at: https://www.cdc.gov/ coronavirus/2019-ncov/infection-control/control-recommendations. html. Accessed on 1 March 2020.

38. Tai DYH. SARS: how to manage future outbreaks? Ann Acad Med Singapore 2006;35:368-73.

39. Zhang W, Du RH, Li B, Zheng XS, Yang XL, Hu B, et al. Molecular and serological investigation of 2019-nCoV infected patients: implication of multiple shedding routes. Emerg Microbes Infect 2020;9:386-9. 